\title{
Multi-criteria fuel system optimization with an electronic control unit
}

This paper presents the results of the multi-criteria synthesis of a diesel engine fuel system using the optimization method. The optimization criteria, functional restrictions and quality criteria have been selected. The efficiency of the proposed method was demonstrated using the example of a diesel engine with the Common Rail system.

Key words: diesel engine, fuel system, solenoid injection, optimization

\section{Introduction}

In technical design practice, various methods of optimization are frequently applied. First of all, approaches are verified on the basis of solving a simple problem - carrying out a series of calculations in order to determine system indicators for various single parameters $[1,2,6,13]$.

The economic aspects of applying virtual experiments are obvious. They allow combinations of parameters to be selected, a great number (up to 4,000 and more) of experiments to be performed and changes in parameters (pressure, displacement, temperatures) to be measured, which is sometimes not possible in practice. As a result, it helps to reduce the research time and design costs and to find optimal parameters for the entire object or its individual system.

The efficiency of the optimization solution depends on the reliability of the mathematical models applied and the dependencies between the variables. This article presents the results of an experiment obtained while determining the optimum parameters of the Common Rail system. Characteristics of most common mathematical models of this system are investigated, among others in $[2,3,5,8,9,10]$.

However, it should be indicated that no optimization method eliminates the human factor, i.e. so-called "expert advice". Expert advice plays a decisive role when choosing parameters, constraints and criteria, but also when selecting the result of the optimization process. Numerous studies have been published on the subject of optimization of the direct fuel injection system. Among them, the following studies can be distinguished [12, 14], where the authors apply methods based on constructing, in each point of the circuit, a functional model of the injection process and determining the search vector based on its analysis. To obtain regression equations, the theory of experiment design is used, making it possible to find the search direction with a limited number of calculations. In the complex "Wtrysk" [Injection] program [13], the method of optimizing system processes is formalized and reduced to the application of constrained non-linear multivariable function programming, including the method of penalty functions. As specified by the authors [10], since non-linear programming theory does not provide an answer to the question of what methods are better; several procedures should sometimes be used in parallel. Unlike the above-mentioned authors, who used vector analysis and regression equations, the study [11] uses linear models of the system in a multiparameter and multi-criteria optimization algorithm. Based on the models or using computational and analytical methods for examining the impact of system parameters on the operating process factors, it is possible to choose and to justify the indirect criteria.

\section{The aim and scope of the study, the object of research}

The aim of the study is to optimize the injection process in a fuel system. To achieve this aim, an optimization method has been suggested, parameters significant for the injection process have been selected and functional constraints and quality criteria have been determined.

The object of the research is the injection process in the Common Rail (CR) fuel system. The system is equipped with an injector with a solenoid valve. The principle and characteristics of the system operation have been described in [7].

The operating principles of the injection system allow to formulate separate significant optimization tasks for the injector. After such a separation, the model (including the injector, fuel accumulator and fuel tube) can provide a basis for an efficient multi-parameter and multi-criteria optimization algorithm.

\section{Optimization method}

The modern method proposed by Sobol and Statnikov [15] was used for optimization purposes. This is a method based on computational scanning of the parameter space for the designed objects, which can be reduced to three stages:

Stage 1- constructing test tables. This stage does not provide for human participation. The procedure starts with $\mathrm{N}$ test points. The value of all criteria is determined at each point. Each criterion is composed of the test table. Tables are an analogue of statistical variation series.

Stage 2- choice of criteria constraints. This stage is carried out through the computer-designer dialogue. When reviewing each of the tables, the designer must set a constraint for each of the criteria.

Stage 3- checking the completeness of acceptable points. The stage is performed automatically.

\subsection{Selection of sampling points}

To date, the most popular method is one in which regular grids are used for the review of the multi-dimensional cube. However, uniform scanning of a multi-dimensional cube is optimal only in a one-dimensional case, at $n=1$ for the space. Regular grids are unsatisfactory at $n=2$. A precise model of the technical object contains a high number of 
parameters in its description. It is known a priori that a considerable number of these parameters do not have any significant effect on the process. In an extreme situation, which often occurs, only one parameter has a significant impact, while others are negligible for a given criterion.

The distribution of $\mathrm{N}$ sampling points in which each of the parameters makes an evenly distributed sequence of $\mathrm{N}$ points at the given section should be considered optimal. Regular grids do not satisfy this requirement. Figure 1 presents a regular grid composed of $\mathrm{N}=16$ points. Points are evenly distributed. One point of the grid is placed in each of $\mathrm{N}$ small squares. The flaw of such a distribution is obvious. Evaluating the $\mathrm{f}(\mathrm{x} 1, \mathrm{x} 2)$ function, which is strictly correlated to one argument, we will obtain only four various values. In a multi-dimensional case, regular grids can provide even worse results, since the information loss when calculating $f(x 1 \ldots x n)$ increases. Determination of partial decisions for this problem will be possible through the use of random generators.

In this study [15], the authors propose a quite efficient distribution of points in space which solves this problem. As in the previous case, in the two-dimensional distribution composed of $\mathrm{N}=16$ points, one point is placed in each small square (Fig. 1). However, in this case, while calculating the function in grid points, we will receive 16 weights, which will provide a better view of the scale of function transformations. An optimum sequence always contains $\mathrm{N}$ $=2 \mathrm{p}$ points, where $\mathrm{p}-$ total positive number. An additional advantage of such a sequence is the possibility to double the number of sampling points.

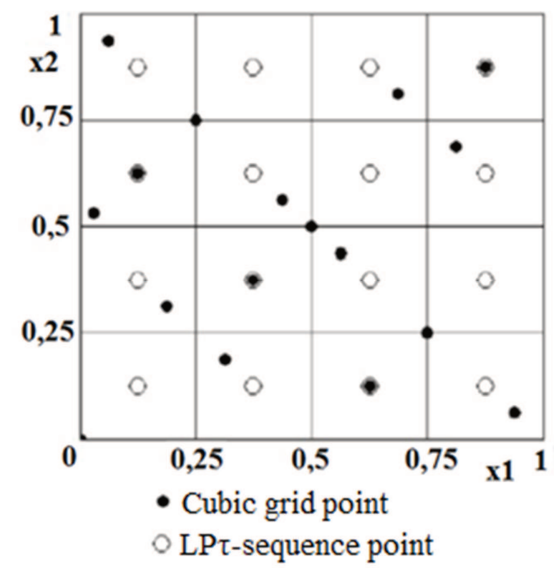

Fig. 1. Regular and improved grid at $\mathrm{n}=2(\mathrm{~N}=16)$

In [15], such a distribution is referred to as $\mathrm{LP} \tau$ sequence. To calculate the $\operatorname{LP} \tau$-sequence, the authors of this paper applied the following arithmetic algorithm. Using the numerator table, we can define $r_{j}(l)$, for which $\mathrm{m}=1+$ [ $\operatorname{lni} / \ln 2]$ is calculated after a set point number and then at each point and for each parameter $\mathrm{j}=1,2, \ldots, \mathrm{n}$ is defined by a dimensionless value. The value of the parameter is calculated from the following equation:

$q_{i, j}=\sum_{k=1}^{m} 2^{-k+1}\left\{\frac{1}{2} \sum_{k=1}^{m}\left[2\left\{i 2^{-l}\right\}\right] \cdot\left[2\left\{r_{j}^{(l)} 2^{k-1-l}\right\}\right]\right\}$

In equations $[\mathrm{z}]-$ the entire $\mathrm{z},\{\mathrm{z}\}-\mathrm{a}$ fraction of $\mathrm{z}$. It is possible to determine the value of the $\mathrm{j}$-th parameter in the $\mathrm{i}$-th point of the $\mathrm{n}$-dimensional space using a variable multidimensional cube with an edge of 1 . Such an algorithm is integrated into the program for fuel system calculations.

\subsection{Choice of injector parameters}

Let us justify the choice of parameters and the scope of their changes. As it is known from [1-3], the process of injection in systems equipped with electronic control is highly affected by the following factors: - displacement of the injector elements; - propagation of pressure and deformation waves through fuel channels and injector elements; - spring vibrations; - physical phenomena accompanying the flow of fuel along small diameter channels (nozzle orifices, orifices of the control chamber); - fuel flow properties in low pressure tubes and related effects of connected masses, contacts and others.

By applying these factors, an improvement of the system operation can be expected. Previously conducted computational and experimental studies have made it possible to distinguish the basic structural and adjustment parameters of the system. Those parameters are shown in Table 1. These are initial set points situated in the centre of a ndimensional parallelepiped. The choice of allowable fluctuation ranges for each of the parameters is made taking into account constraints related to the structure, production or operating conditions of the fuel system.

For instance, the value of the displacement of the valve cannot be lower than $0.025 \mathrm{~mm}$ (protection of the minimum distance between the magnet and the valve) on one side and more than $0.075 \mathrm{~mm}$ on the other (this is related to reducing the force while increasing the distance as a result of the operation). The minimum path of the needle and the stem is $0.125 \mathrm{~mm}$. This reduction is related to the need to minimize the effect of the feasible cross-section area of the nozzle on the change of the fuel pressure also related to stem operation characteristics [5]. Within the ranges of the examined circulation, the transformation of each parameter from Table 1 was $\pm(40-50) \%$. This permits to investigate a wide scope of the multi-dimensional space and determines the direction for searching the optimum. Using the $L P \tau$ sequence generator, sampling points were obtained and samples were marked in the tables. For the previous scanning of parameter space, 128 points were received.

Table 1. Fuel system parameters

\begin{tabular}{|c|l|c|c|}
\hline 1 & Parameter & unit & value \\
\hline 2 & Valve diameter & $\mathrm{mm}$ & 1.3 \\
\hline 3 & Valve displacement & $\mathrm{mm}$ & 0.05 \\
\hline 4 & Spring stiffness coefficient & $\mathrm{N} / \mathrm{mm}$ & 50 \\
\hline 5 & Valve socket angle & degree & 100 \\
\hline 6 & Cross-section area of the intake orifice & $\mathrm{mm}^{2}$ & 0.034 \\
\hline 7 & Cross-section area of the outlet orifice & $\mathrm{mm}^{2}$ & 0.055 \\
\hline 8 & Piston diameter & $\mathrm{mm}$ & 3.8 \\
\hline 9 & Piston length & $\mathrm{mm}$ & 76 \\
\hline 10 & Diameter of the needle closing device & $\mathrm{mm}$ & 1.6 \\
\hline 11 & Needle displacement & $\mathrm{mm}$ & 0.25 \\
\hline 12 & Initial needle displacement pressure & $\mathrm{MPa}$ & 5 \\
\hline 13 & Tube length & $\mathrm{mm}$ & 220 \\
\hline 14 & Internal diameter of the tube & $\mathrm{mm}$ & 1.5 \\
\hline
\end{tabular}




\subsection{Determining functional constraints}

To determine the constraints while formulating the initial data to solve the problem of searching for optimum parameters, functional restrictions should be included. For the injector, functional constraints include the dependencies between the following parameters: -stem diameter exceeds the nozzle needle diameter, which is assumed at the constant level of $3.5 \mathrm{~mm}$; - the feasible cross-section area of the inlet orifice of the control chamber is smaller than the effective cross-section area of the outlet orifice of this chamber; - the diameter of the needle closing device is smaller than needle diameter; - the speed of injector elements is reduced by hitting the support - run limiters. While solving the optimization, functional constraints can be taken into account in two ways.

The first method - after carrying out calculations, permits excluding from the analysis those points in which the value of the parameters is feasible. The second method - at the stage of formulating initial data the constraints indicated are taken into account by setting $\mathrm{k} 1, \mathrm{k} 2, \mathrm{k} 3$ coefficients, which involves dependencies of the above-mentioned parameters. The latter method is considered to be the best. It makes it possible to obtain a larger number of points for the criteria evaluation and reduces the time for solving the optimization.

\subsection{Choice of quality criteria}

Pursuant to reports by other authors (e.g. [10]), two decisive quality criteria should be ultimately selected for the injector - maximum injection pressure $\mathrm{Pw}$ and $\mathrm{Qz}$ fuel doses for control purposes. At the same time, $\mathrm{Pw}$ pressure should be at its maximum value. Let us explain the choice of the Qz criterion. In the control chamber, the fuel pressure is $25-150 \mathrm{MPa}$. The injection process takes place when the fuel is discharged from the control chamber to the fuel return system. Therefore, a lower volume of fuel is discharged with the lowest energy expense required for driving the fuel pump. However, there is a minimum value of Qz required for the safety of electromagnet cooling.

To obtain multiple Pareto points, which represent a single-dimensional variability on a plane, it is convenient for both criteria to aim towards the minimum, while maintaining a non-dimensional form. Let us introduce the following criteria: $-\mathrm{Kp}=\mathrm{Rz} / \mathrm{Pw}$, where $\mathrm{Rz}$ - fuel pressure in the accumulator; - Kq $=\mathrm{Qz} / \mathrm{Qc}$, where $\mathrm{Qc}$ - fuel dose. Through the introduction of those criteria it is possible to evaluate the relative fuel rate on fuel control and to compare the $\mathrm{Pw}$ value with the $\mathrm{Rz}$ pressure level.

In problems with two criteria $\Phi 1 \rightarrow \min , \Phi 2 \rightarrow$ min, the decision consists in the so-called Pareto multitude of parameters; each such set is a solution to a single-criterion problem $\Phi 1 \rightarrow$ min at $\Phi 2=$ const. Each set of parameters allowed after functional constraints (referred to as effective ones), corresponds to a point on a criteria plane (Kp, Kq) (Fig. 2). Pareto points on the criteria plane (Fig. 2) will correspond to the compromise curve section.

\section{Optimization results}

Let us demonstrate the final stage of the search for an optimum relation between $\mathrm{CR}$ injector parameters. As a result of scanning, out of the multitude of 128 acceptable points, 24 proved to be effective. Figure 2 shows the location of those points on the criteria plane $(\mathrm{Kp}, \mathrm{Kq})$. It can be seen that in each of those points, the efficiency of the injection process according to the criteria indicated $(\mathrm{Kp}=0.912$ $0.941 ; \mathrm{Kq}=0.178-0.137)$ significantly surges in comparison to point $1(\mathrm{Kp}=1.08 ; \mathrm{Kq}=0.447)$, which corresponds to the initial set of injector parameters (Table 1).

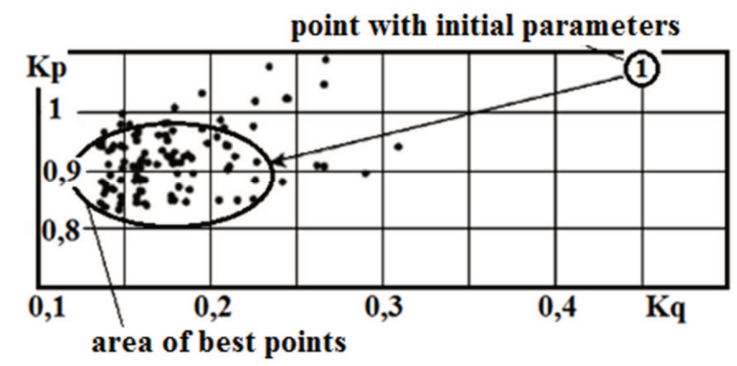

Fig. 2. Fragment of a distribution of sampling points on the criteria plane $(\mathrm{Kp} ; \mathrm{Kq})$

The compromise curve features three points, which are located on the by-passing curve A (Fig. 3) limited with lines $\mathrm{D}$ and $\mathrm{E}$. The numbers of those points are $-61,121$, 106 , and the part of the curve joining these points is the compromise confidence curve. Points № 48 and № 127 are also located on curve $\mathrm{A}$, but curve $\mathrm{A}$ is not a compromise curve to the right of point № 106. Indeed, on a part of curve A separated with a dotted line there are points for which two criteria vary either up to the maximum or to the minimum side. For instance, for the minimum value of criterion $\mathrm{Kq}=0.2$, a point of intersection of curve A with the indicated weight of $\mathrm{Kq}$ should be found to obtain the best quality.

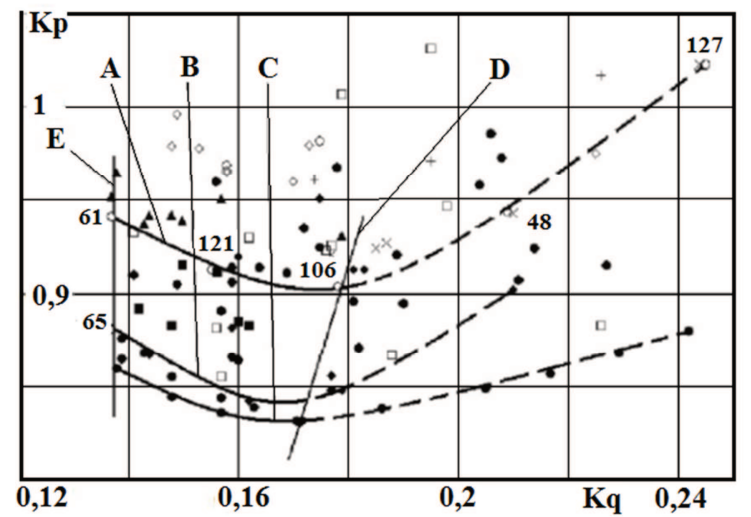

Fig. 3. Sampling points and compromise confidence curves on the criteria plane $(\mathrm{Kp} ; \mathrm{Kq})$

In point № 61, seven parameters are located near the centre of the scanned area, two parameters assume the maximum assumed values and two assume the minimum values. In point № 106, nine out of twelve parameters are located in the centre, two acquire the minimum value and one acquires the maximum. In point № 121, the number of mean values is eight, two assume the minimum and two assume the maximum values. In the obtained number of solutions, there exists an isolated point № 65 (Fig. 3). Ac- 
cording to the quality criteria, this is the best point. However, five parameters of point № 65 assume the minimum acceptable value. The pin spring tensile pressure is 1.57 $\mathrm{MPa}$, and the dimension of the valve range is $0.864 \mathrm{~mm}$. Starting from the recommendation [15], also in view of the experience of the authors of the solution of this multicriterion problem, this number would have to be increased up to 2-4 times, which will help to increase the efficiency of the optimization.

Partially, a solution to the problem is provided by the consistent optimization algorithm, the application of which to this problem is reduced to further refinement of the compromise curve. Additionally, the area of parameters in the vicinity of Pareto points № 61, 106 and 121 should be scanned. The centre of the new parallelepiped features the indicated Pareto point, the parameters of which can change within a narrow range of $\pm 15 \%$. In such a case, the volume of the scanned perimeter is reduced 106 times, and the number of sampling points, defined with the use of the LP $\tau$ sequence generator, can be reduced to 16 .

As a result of such refinement, many new allowable points have been obtained, located below A curve (Fig. 3), and a new compromise curve B was developed. It is interesting to note that point № 65 obtained during the previous scanning is situated on curve B and limits it on the left. Therefore, the procedure for refining the compromise curve should be repeated once again. At the same time, the area of points located in curve $\mathrm{B}$, limited with lines $\mathrm{D}$ and $\mathrm{E}$, should be scanned. The refinement results in curve $C$. The distance between curves $\mathrm{B}$ and $\mathrm{C}$ is slight, which indicates that the decision on abandoning the refinement of the compromise curve can be made.

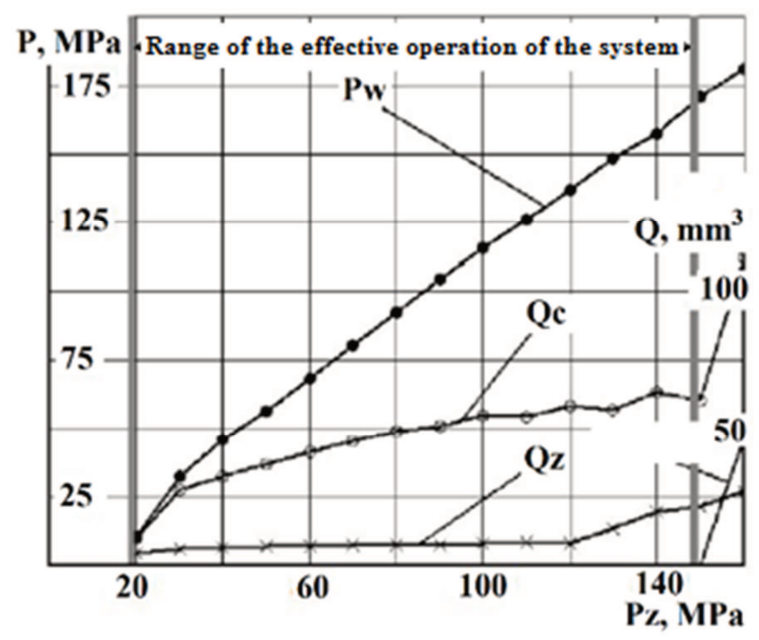

Fig. 4. Relation between injection parameters and pressure Rz for the system with an optimized injector

The obtained results indicate that curve A contains points with optimal parameters. The final point of the optimization solution is determination of the perimeter for the system operation with an optimized injector at pressure $\mathrm{Rz}$ change. Therefore, the values of parameters obtained for Pareto points on curve $\mathrm{C}$ were included in calculations, by setting the value of $\mathrm{Rz}$, thus enabling calculation of dependencies between $\mathrm{Pw}, \mathrm{Qc}, \mathrm{Qz}$ and Rz. The maximum possible $\mathrm{Rz}$ was determined by the presence of unnecessary fuel rate $\mathrm{Qp}$ at the nozzle in the final phase of the injection. The obtained results make it possible to claim that the optimized system protects the fuel injection at minimum pressure of $\mathrm{Rz}=20 \mathrm{MPa}$, and the maximum pressure of $\mathrm{R}=$ $150 \mathrm{MPa}$ (Fig. 4).

The performed optimization of the injector permits increasing the injection pressure $\mathrm{Pw}$ in comparison to the pressure in the accumulator Rz by $15 \%$ (Fig. 5).

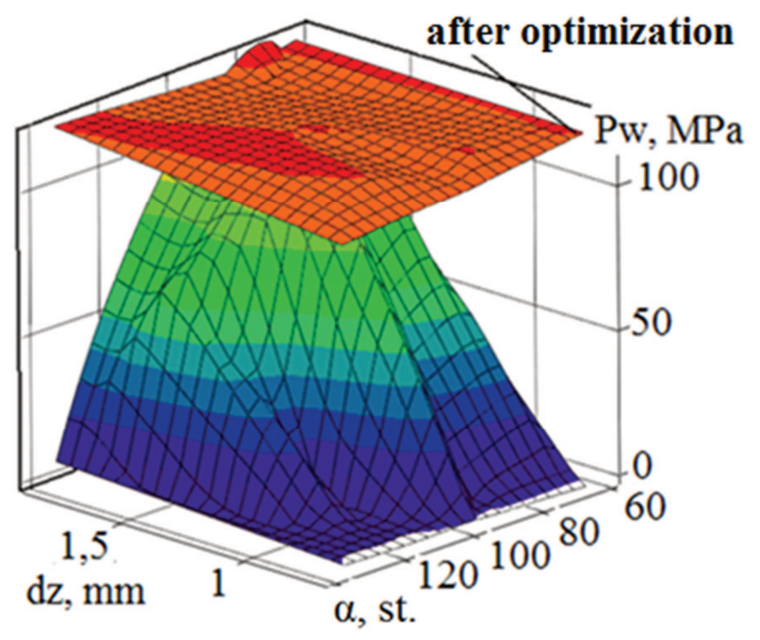

Fig. 5. The relation between injection pressure $\mathrm{Pw}, \mathrm{dz}$ diameter and the injector valve socket angle $(\mathrm{Pz}=100 \mathrm{MPa})$

For all calculation points in the optimization process, a single-phase injection was set with electric pulse parameters (maximum value of current in the solenoid 17.5 A, and during the steady period $10 \mathrm{~A}$, duration of the electric signal $1 \mathrm{~ms})$.

\section{Conclusions}

1. A new method for multi-criteria optimization of the fuel system with an electronic control unit has been developed. It is based on computer scanning of the parameter change perimeter and construction of Pareto compromise curves.

2. The major parameters of the fuel system with the most significant impact on the injection process (Table 1) have been determined. Functional constraints have been formulated, along with the quality criteria - maximum injection pressure $\mathrm{Pw}$ and fuel rate on fuel control Qz, which enables evaluation of the injection process efficiency.

3. The fuel system optimization makes it possible to increase the maximum injection pressure $\mathrm{Pw}$ in comparison to the pressure level in $\mathrm{Rz}$ accumulator by $15 \%(\mathrm{Rz}$ exceeds $\mathrm{Pw}$ in the initial system) and to achieve twofold reduction of the fuel rate on fuel control.

4. The range of effective operation of the system in relation to pressure $\mathrm{Rz}$ has been determined. The system protects fuel injection at $\mathrm{Rz}$ pressure changes ranging from 20 to $150 \mathrm{MPa}$. 


\section{Nomenclature}

$\mathrm{CR}$ common rail

$\mathrm{LP} \tau$ sequence points in a multi-dimensional case

$\mathrm{PW}$ maximum injection pressure

$\mathrm{Pz}$ fuel pressure in the accumulator
Qc fuel dose of injection

Qz fuel dose for control purposes

$\mathrm{Kq}, \mathrm{Kp}$ quality criteria

\section{Bibliography}

[1] BIANCHINI, G.M., PELlONI, P., FILICORI, F., VANNINI, G. Optimization of solenoid valve behavior in common-rail injection systems. Proc. of the SAE 2000 World Congress, 2000-01-2042.

[2] BORCHSENIUS, F. STEGEMANN, D., GEBHARDT, X. Simulation of diesel common rail injection systems. MTZ. 2010, 6, 42-45.

[3] COPPO, M., DONGIOVANNI, C., NEGRI, C. Numerical analysis and experimental investigation of a common railtype diesel injector. Journal of Engineering for Gas Turbines and Power. 2004, 126(4), 874-885.

[4] HU, Q., LOU, D., TAN, P., HU, Z. et al. Study on fuel injection parameters optimization for common rail diesel engine fueled with B20 biodiesel. SAE Technical Paper. 2014, 2014-01-2655,

[5] Seykens X.L.J., Somers L.M.T., Baert R.S.G. Detailed modeling of common rail fuel injection process. MECCA, III. 2005, 30-39.

[6] STATNIKOV, R., BORDETSKY, A., STATNIKOV, A. Multicriteria analysis of real-life engineering optimization problems: statement and solutions. Nonlinear Analisys. 2005, 63, e685-e696.

[7] Układ wtryskowy Common Rail Bosch. WKit, Warszawa 2000.

[8] ВРУБЛЕВСКИЙ, А.Н., ГРИГОРЬЕВ, А.Л., ГРИЦЮК, А.В., ДЕНИСОВ, А.В.,. ЩЕРБАКОВ, Г.А. Особенности математического моделирования гидромеханических процессов ЭГФ. ДВС. 2007, 1, 44-52.

Aleksander Wróblewski, DSc., DEng. - Faculty of Technical Sciences at University of Warmia and Mazury in Olsztyn.

e-mail: Aleksander.Wroblewski@uwm.edu.pl

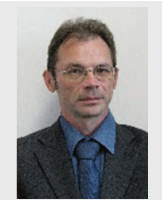

[9] ВРУБЛЕВСКИЙ, А.Н. Математическая модель движения элементов и течения топлива в полостях низкого давления электрогидравлической форсунки. Автомобильный транспорт - Харьков: ХНАДУ. 2008, 22, 109-117.

[10] ГРЕХОВ, Л.В., ИВАЩЕНКО, Н.А., МАРКОВ, В.А. Топливная аппаратура и системы управления дизелей. Легион - Автодата, Москва 2004.

[11] ГРИГОР'ЄВ, О.Л., Розробка універсальних методів гідродинамічного розрахунку, динамічного аналізу та оптимізаційного синтезу основних елементів паливної апаратури дизелів. Автореферат дис. докт. техн. наук. Харків. НТУ «ХПІ». 2004, 36.

[12] ГОРБАНЕВСКИЙ, В.Е., КИСЛОВ, В.Г., БАШИРОВ, P.М. и др. Дизельная топливная аппаратура: Оптимизация процесса впрыска, долговечность деталей и пар трения. МГТУ. Москва 1996

[13] КУЛЕШОВ, А.С., ГРЕХОВ, Л.В. Математическое моделирование и компьютерная оптимизация топливоподачи и рабочих процессов двигателей внутреннего сгорания. М.: изд-во МГТУ. $2000,64$.

[14] МОРОЗОВ, Ю.В. Реализация заданных характеристик впрыскивания топлива путем оптимизации конструктивно-регулировочных параметров топливной аппаратуры: Автореферат дисс... докт. техн. наук. Харьков. ХарГАЖТ. 1998, 32.

[15] СОБОЛЬ, И.М. СТАТНИКОВ, Р.Б. Выбор оптимальных параметров в задачах со многими критериями. Наука. Москва 1985. 